\title{
Weak rock open pit slope stability considerations to inform workplan for evaluating the position of permanent mine infrastructure: a northern Canada mine case study
}

\author{
E Saunders SRK Consulting (Canada) Inc, Canada \\ A LeRiche SRK Consulting (Canada) Inc, Canada
}

\begin{abstract}
Operating open pits are exposed to geotechnical stability risks throughout the life of mine. These risks can be considered part of normal operating conditions and are managed by mining teams. Following the completion of mining, weak rock slopes can exhibit progressive failure mechanisms due to severe erosion or deterioration and are negatively influenced by the post-mining hydrogeological and hydrology conditions. In this context, these failure mechanisms can impact existing or planned mine infrastructure (e.g., water treatment, diversion channels, closure landforms) that is needed to achieve mine closure objectives.

This paper describes key geotechnical and hydrogeological aspects that need consideration in developing a work plan for rigorous mine closure open pit stability assessment in weak rocks. The paper is supported by a case study of a pit stability assessment at the Faro Mine Complex, a former lead-zinc open pit located in Yukon Territory, Canada. For this case study, the importance of the stability assessment work to the positioning of a new permanent non-contact water diversion channel is described, including locating the alignment outside of the predicted long-term pit slope break-back.
\end{abstract}

Keywords: geotechnical, weak rocks, design criteria, slope stability, open pit

\section{Introduction}

Stability and design processes for open pits are well established and have been published by the Large Open Pit Project (LOP) and others. The intention of the paper is to describe other key factors, sometimes unique, that should be considered where developing a weak rocks stability assessment workplan for mine closure designs. For the purposes of this paper, weak rock is described as those materials which exhibit intact strengths less than approximately $25 \mathrm{MPa}$ strength and may be heavily fractured, altered, faulted, erodible or degradable. These materials can include saprolites, mud-rocks, cemented sediments, soft iron ores and hydrothermal altered rocks (Martin and Stacey, 2018). Key considerations discussed are conceptually shown in Figure 1 and listed below:

- Closure stability context

- Geological and structural model

- Hydrogeology and pit lakes

- Weathering, erosion, and rates

- Rock mass deterioration (or fatigue)

- Acceptance Criteria and regulations

Comments specific to mine closure pit slope stability assessment are provided in Figure 2 . These comments have been aligned to the slope design process outlined by Read \& Stacey, 2009. 


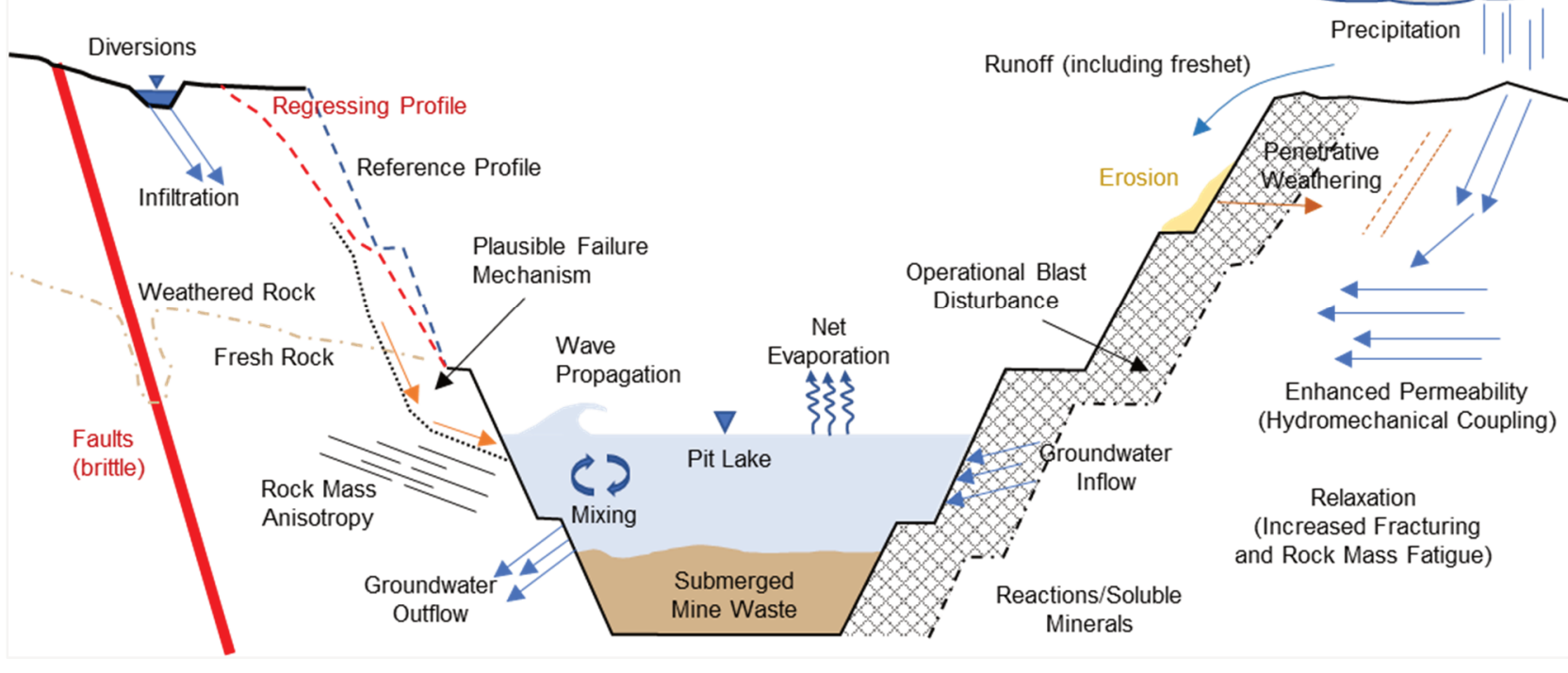

Figure 1 Conceptual open pit model showing various processes and closure stability assessment inputs

Large Open Pit Slope Design Process (Read \& Stacey, 2009)

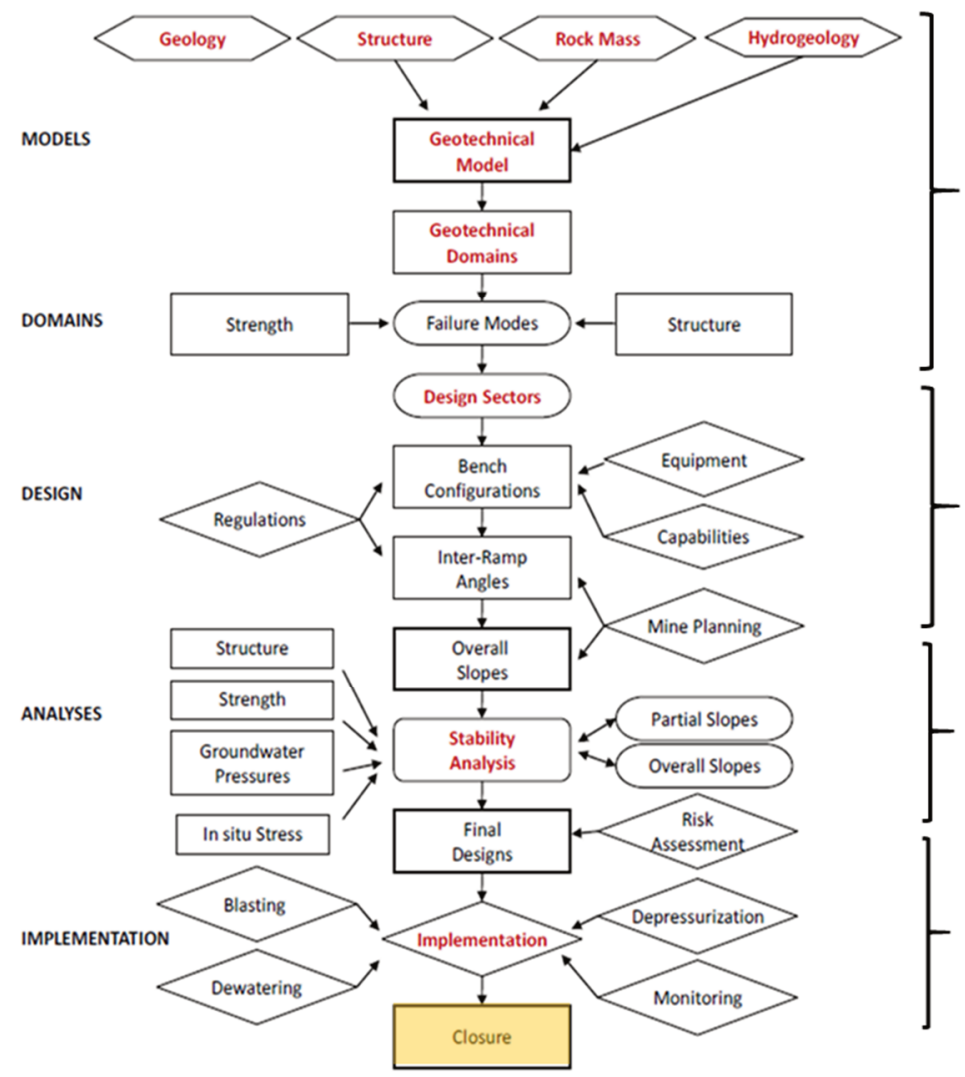

Closure Pit Slope Stability Assessment Comments

Need to revisit all Models and Domains aspects, including 3D interpretation, reliability and changes to long-term rock mass character.

Need to adhere to Regulatory requirements or guidance. Possibly other design aspects if mitigating or remedial designs are needed. Historical Design to be understood with regards to observed performance.

To perform Analyses to an industry standard. Typically focussing on the consequential, overall scale. Analyses efforts maybe driven by Risk Assessment.

Typically no significantly new Implementation unless mitigating design is required. Lack of long-term

Depressurization or Dewatering incorporated in Analysis. Monitoring commitments critical to asset management.

Figure 2 Slope design process (Read and Stacey, 2009) with comments for closure pit slope assessment 


\section{Key Considerations}

\subsection{Closure Stability Context}

Stability analyses performed to evaluate current, and the predicted long-term condition requires sound judgement to identify plausible failure mechanism(s). This should include identification of the governing factors such as major structures (e.g., faults), with respect to their location, dimension/volume, rupture surface geometry and back-break. Where failure is imminent or predicted to occur, mobilization and velocity behaviour should also be understood to evaluate consequences related to run-out or a pit-lake wave propagation event. Plausible failure mechanisms in weak rock need to consider, amongst others:

- Pit backfilling with waste rock and tailings, or lack of.

- Weathering and erosion.

- Rock mass strength deterioration related to, stress relaxation, alteration, or mineralogy.

- Pore pressure conditions including influence from pit lake, infiltration, and seepage.

- Structural controls and longer-term reduction in shear strengths.

- Historical slope performance, during and post-operations.

- Interaction with underground operations and related deformation.

- Local tectonic setting and potential seismic risk

Figure 3 presents the three stability phases that requires consideration when developing a comprehensive workplan. Data appropriateness or biases at each phase needs to be acknowledged. For example, the field investigation data collected as part of pre-mining design work may not be fully representative of the materials closer to the slope face that have likely been disturbed by blasting and stress relaxation as open pits become larger and deeper.

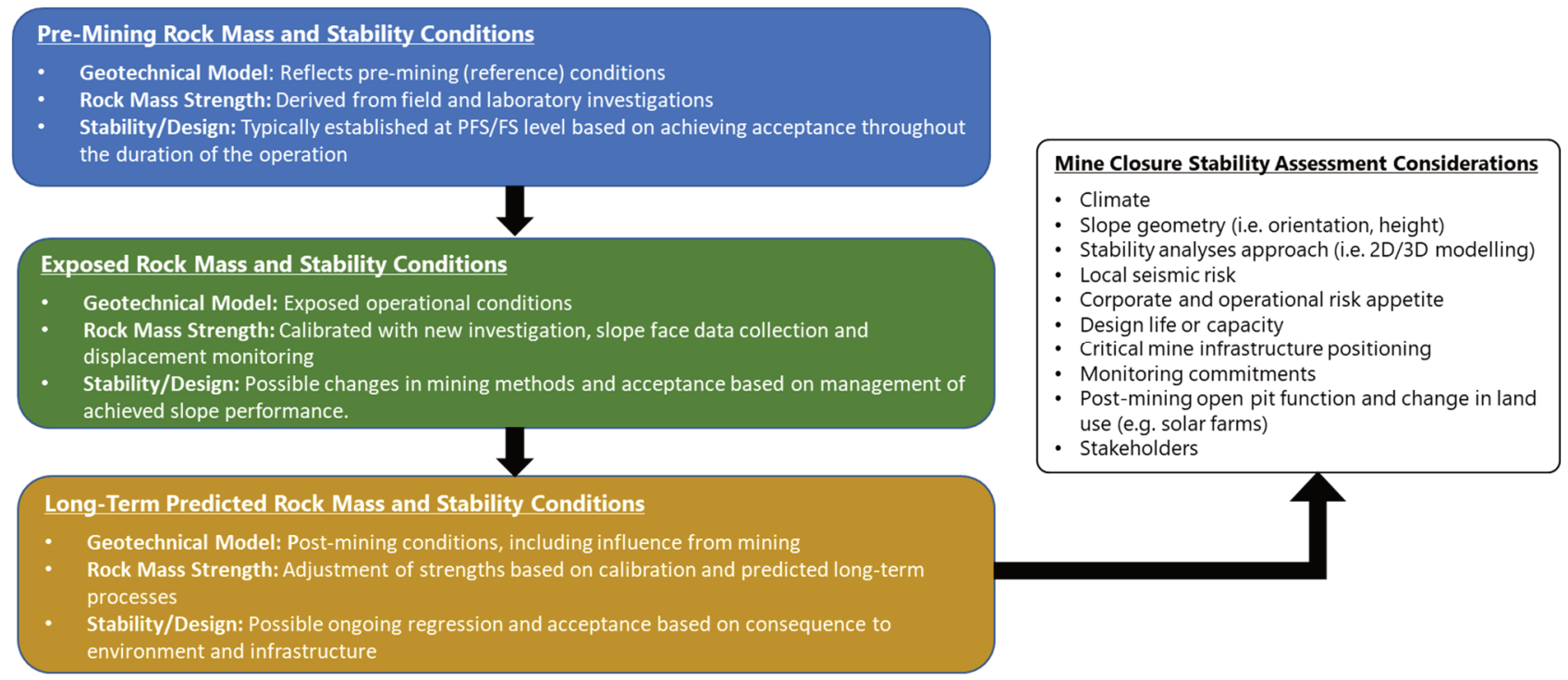

Figure 3 Reference, Exposed and Long-Term Predicted Rock Mass and Stability Conditions which require consideration in evaluating mine closure pit slope stability

\subsection{Geological and Structural Model}

A significant amount of literature is available which discusses 3D geological and structural model data, interpretation, and reliability requirements (e.g., Read \& Stacey, 2009, Martin \& Stacey, 2018). Historical information, both public and corporate, should be reviewed as part of reconciling existing models and 
adjusting, as required. Identification of the model confidence should be factored in the design reliability and selection of stability design acceptance criteria (DAC). In some instances, there can be a lack of historical data or the given mining approach (e.g., caving) makes it difficult to generate a model to the required resolution. Figure 4 shows an open pit mine which subsequently transitioned to cave operations. The cave draw-down has led to challenges with generation of a reliable post-mining 3D model near the pit slopes of interest. In such cases where geological model confidence is lower, stability acceptance criteria may have to be greater.

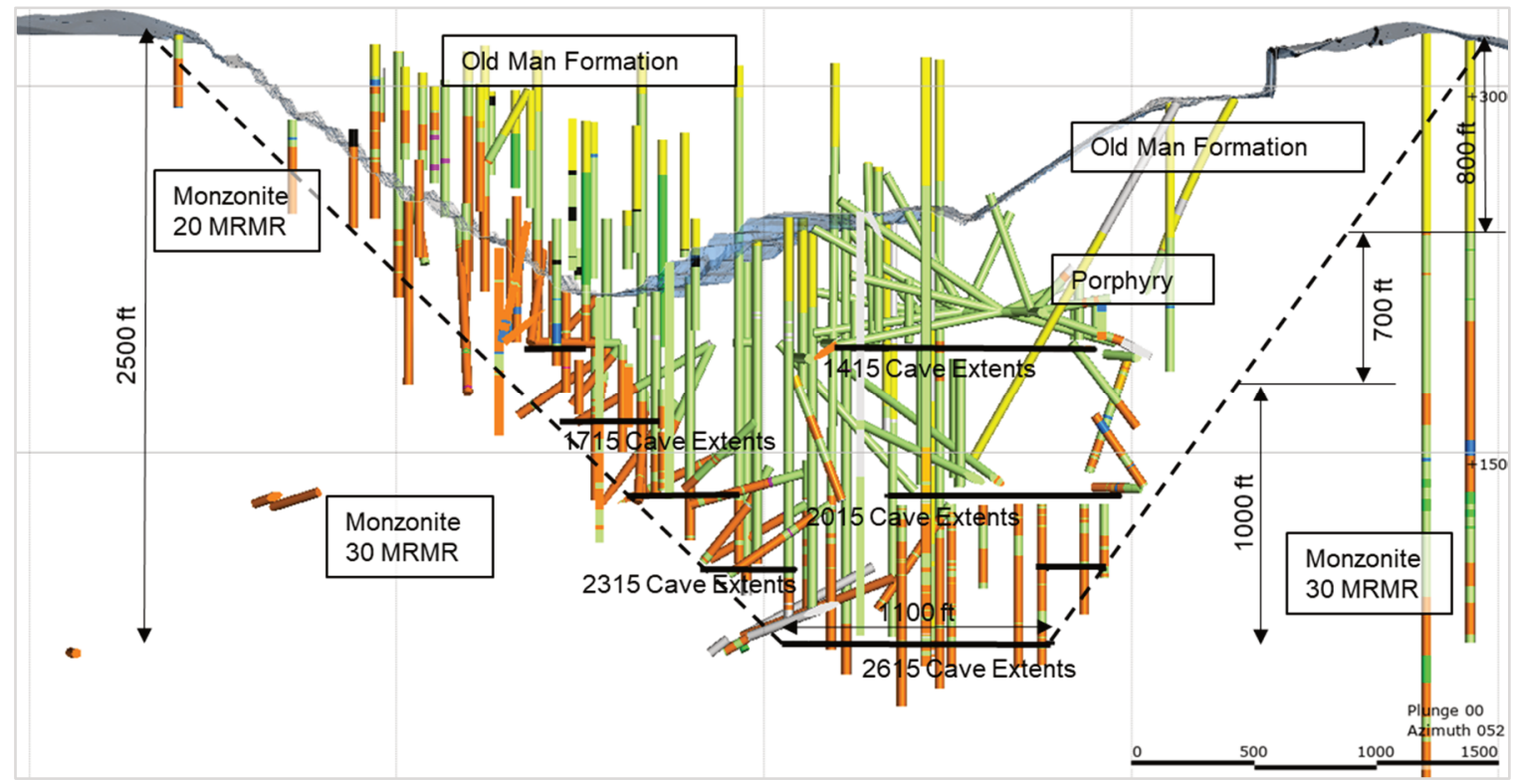

Figure 4 Challenges with reconstruction of geological and structure models where open pits are caved

Understanding of the structural controls on weak rock stability is required to determine the plausibility of analysed failure mechanisms (e.g., relic structures in deeply weathered saprolites). Where historical data is lacking, conceptual models should be built and tested in 2D software modelling packages to evaluate a range of outcomes. For example, Murphy \& Barnett (2018) show typical structural controls on orogenically deformed rock masses; these types of conceptual models should be treated as a starting point to identify plausible long-term conditions (Figure 5).

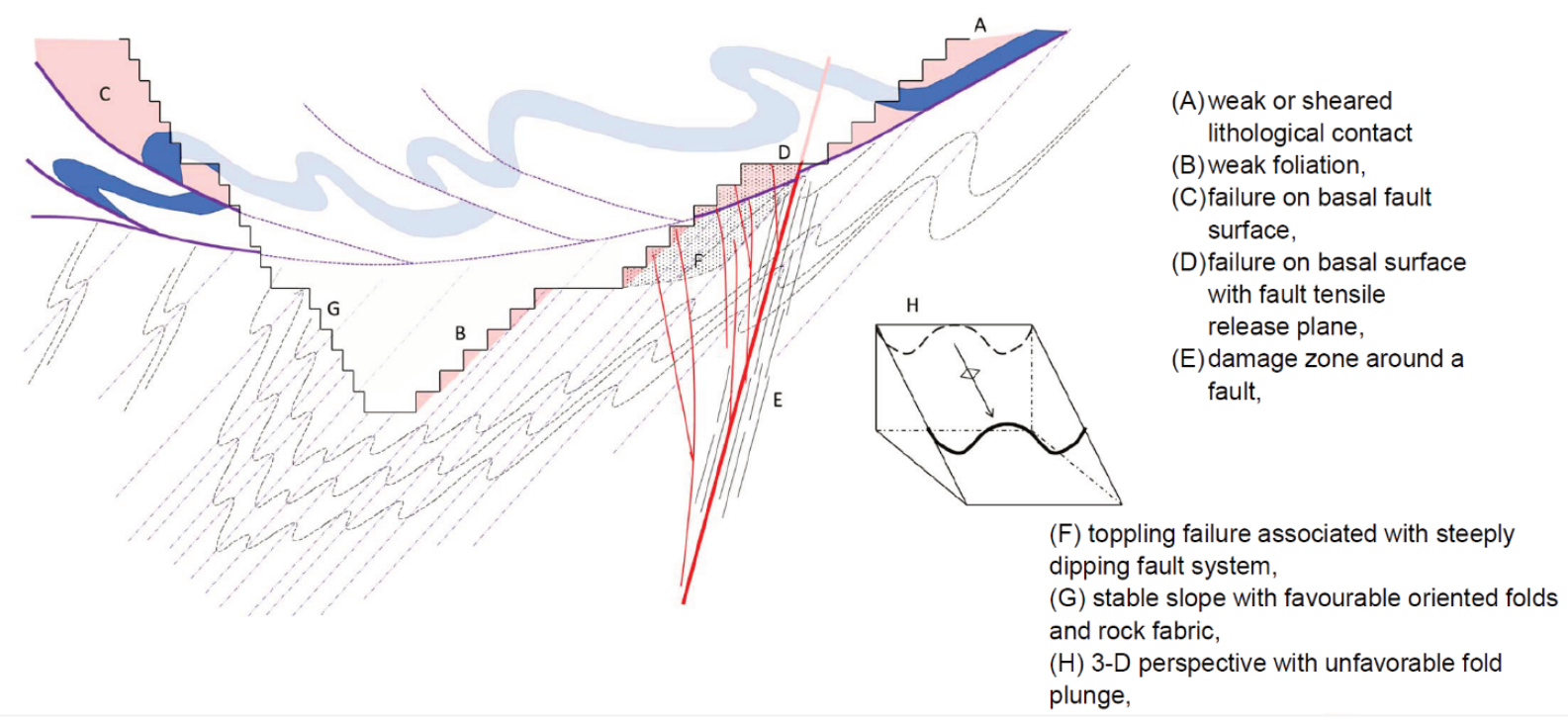

Figure 5 Schematic illustration of typical structural geology influences on open pit stability in orogenically deformed rock mass (from Murphy \& Barnett 2018) 


\subsection{Hydrogeology and Pit Lakes}

Pit lakes are developed, intentionally or otherwise, when open pits fill with water after excavation and dewatering cease (McCullough et al., 2020). When the open pit extends below regional groundwater levels, groundwater inflows contribute to the final pit lake elevations. Where environments have low evaporation rates or aquifers have higher permeability, pit lakes can fill in a few years. In arid regions, some pit lakes will not fill passively, and are termed 'terminal pit lakes because they act as a groundwater sink (McCullough et al., 2013). In the sub-artic (where net evaporation is low) it is expected that pit lakes will fill passively and can required artificial acceleration of filling to advance the closure management process (Van der berg, 2015). Victor Mine is a northern Canada example of this process (de Graaf et al, 2019). Pit lakes and hydrogeological conditions are site-specific, and these conditions require investigation in the context of the stability workplan. For example, will the most adverse stability conditions occur at a pit lake corresponding to 5 or 50 years?

Transient pore pressure changes as groundwater systems equilibrate to potentially very different conditions than the pre-mining environment should be understood (e.g., hydromechanical coupling resulting in enhanced conductivity). The predicted slope stability (as represented by a Factor of Safety (FoS)) can fluctuate with incremental pit lake level rise. Figure 6 shows two predicted pit lake elevation models for a closed operation from 2002 to 2024 along with resultant FoS representing a critical modelled overall-scale failure. In this example the FoS decreases where there is saturation of the lower portions of the modelled failure surface. The FoS results are generally higher where water elevation is below the toe of the modelled failure or at a lake elevation where hydrostatic conditions are interpreted to restrain the examined slope face.

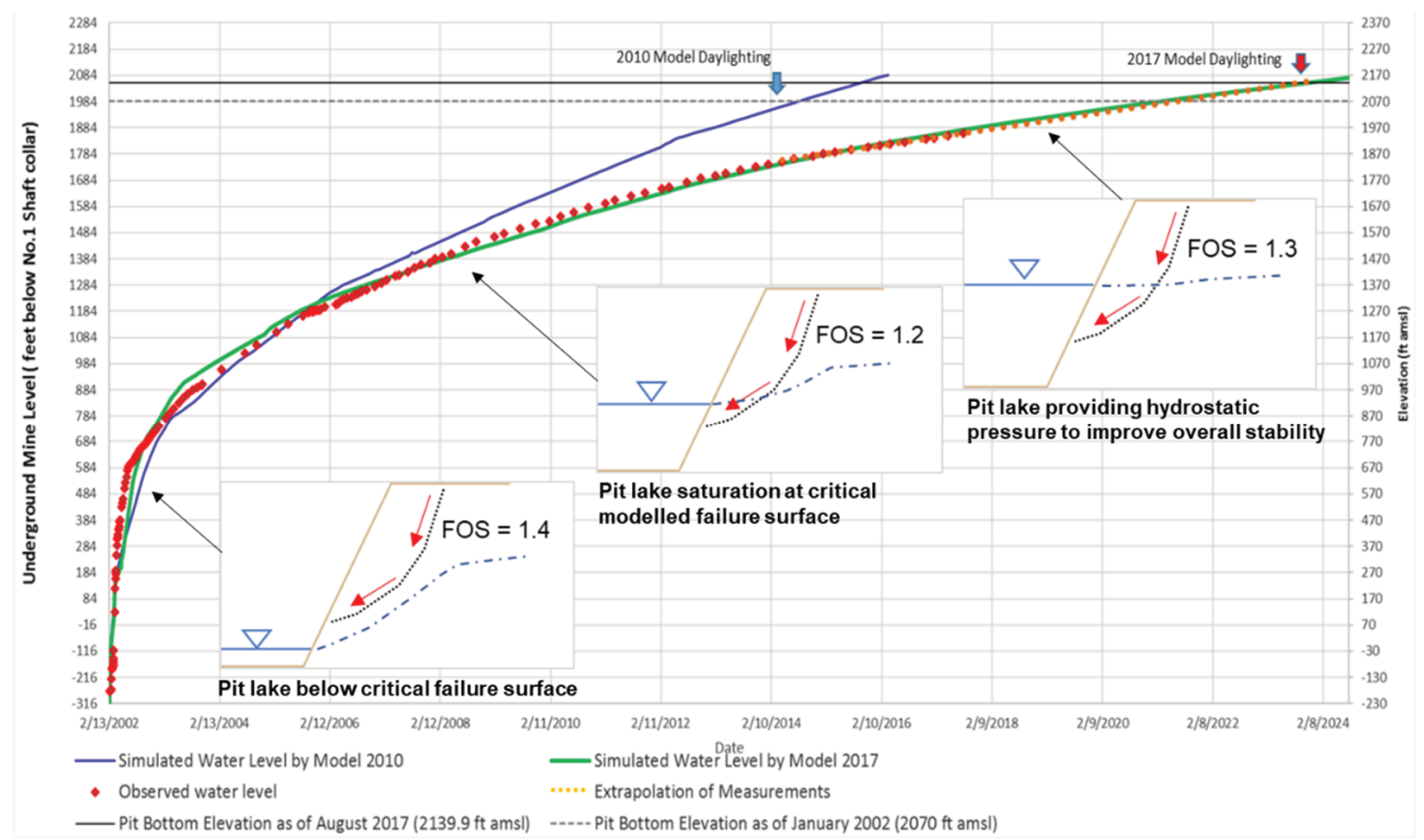

Figure 6 Predicted groundwater level rise and associated Factor of Safety for a pit wall stability event.

\subsection{Weathering, Erosion Rates and Penetration}

Weathering of intact rock or discontinuity surfaces can be categorized by two dominant processes:

- Physical: mechanical breakdown into progressively smaller fragments. The processes relate to temperature variations, wetting/drying and freezing/thawing, crystallization pressures, hydration, swelling and shrinkage of minerals due to water absorption (Hack 2000). 
- Chemical: dissolution, oxidation and reduction, hydration, and hydrolysis reactions. The processes are largely affected by the mineralogy of the parent rocks and influenced by climate, surface and groundwater, and chemical compositions (Fookes et al., 1988).

Climatic influence (and change) should be investigated when evaluating rock mass weathering (both observed and predicted). Peltier (1950) conceptually relates temperature and rainfall to weathering processes (Figure 7). Shinjo \& Ito (1989) investigated artificial weathering on mudstone strength at the laboratory scale (Figure 7).

For large open pits, weathering can be enhanced through erosion, blasting, stress relaxation, modified groundwater flow systems or unique site processes such as in-situ leaching. It is common to compare the investigated rock strength with observed weathering grade. However, it is more difficult to quantify future weathering grade and its influence on rock strength (Huisman 2006). Huisman also outlines the time and spatial scales of weathering research with representative field studies lying far outside of the typical closure study program duration (Figure 8). Furthermore, it can be challenging to distinguish between erosion and the penetration of a weathering front which that can have material influence on rock mass conditions.
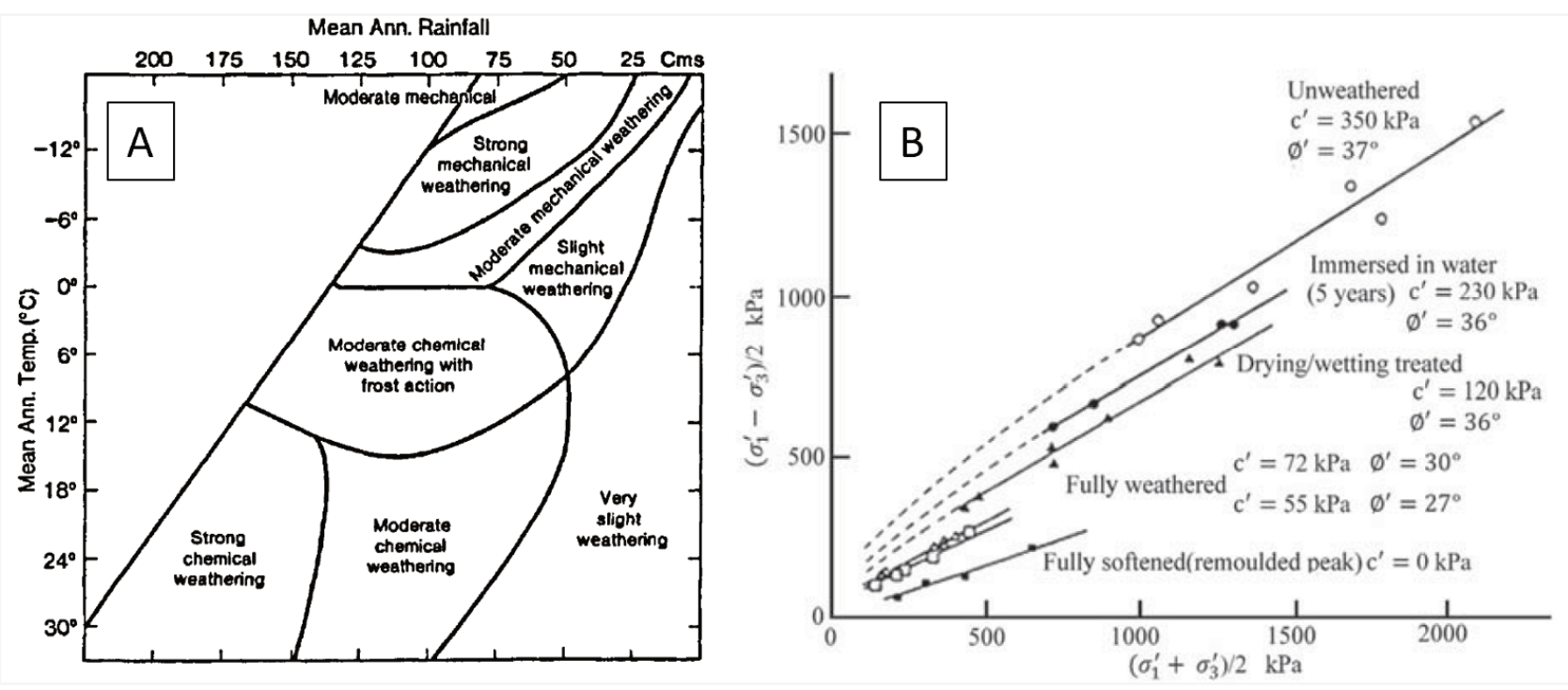

Figure 7 Categories of weathering in relation to temperature and precipitation (Peltier, 1950) and example laboratory testing of mudstones under experimental climatic conditions (Shinjo and Ito, 1989)
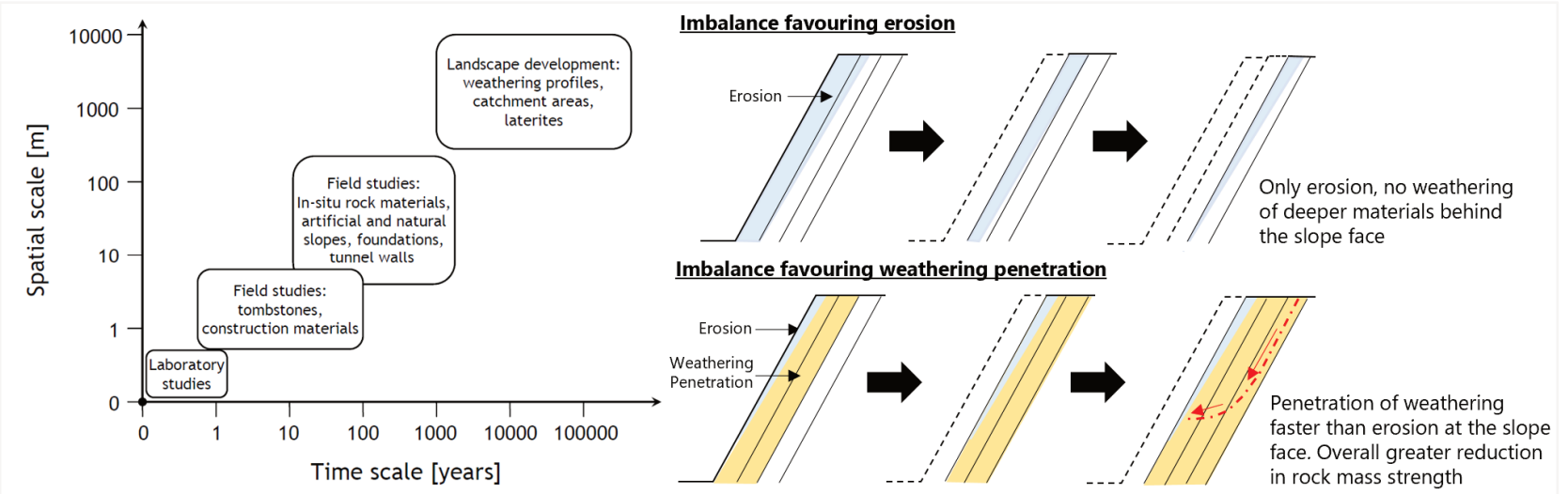

Figure 8 Approximate time and spatial scales of weathering research (left), conceptual illustration of erosion vs weathering penetration (right) (Modified from Huisman, 2006) 


\subsection{Weak Rock Mass Strength Deterioration}

As described by Martin \& Stacey (2018), most weak rocks are erodible, and many degrade on exposure. Field and laboratory investigations from the exposed lope face or directly behind are required to evaluate exposure rock mass strengths and compare against those investigated at pre-mining phase (Figure 3). Alternatively, core can be re-examined at later dates to observe changes, in condition however, this can be difficult to quantify. As an example, Figure 9 shows a comparison of rock core immediately after drilling (2015) and after five years of exposure to atmospheric conditions from core stored on pallets outside (2020). Where good datasets are available, relative changes in strength can be evaluated semi-quantitatively. Discussions and worked examples for rock mass strength reduction are outlined by de Bruyn et al. (2019). Some aspects which influence the rate and degree of rock mass deterioration have been summarized in Table 1.

Discontinuities such as faults, joints, bedding, and foliation can be observed as open features during coring. 'Incipient discontinuities' are those not yet developed and maybe become pervasive within a rock fabric when subject to changes in stress (e.g., blasting, excavation, weathering). The development of incipient discontinuities can contribute to weakening of a rock mass as shown in Figure 10 and should be accounted for when assigning long-term strength parameters (i.e., Geological Strength Index).

Table 1 Deterioration Comments related to timescale, rock mass strength and groundwater

\begin{tabular}{|c|c|c|c|}
\hline Aspect & & Weak Rocks & Strong Rocks \\
\hline \multirow{3}{*}{ Timescale } & Pre-Operation & Reference rock mass conditions & Reference rock mass conditions \\
\hline & Operation & $\begin{array}{l}\text { Significant deterioration observed with } \\
\text { potentially adverse stability conditions }\end{array}$ & Little obvious deterioration \\
\hline & $\begin{array}{l}\text { Post- } \\
\text { Operation }\end{array}$ & $\begin{array}{l}\text { Continued deterioration with erosion exposing } \\
\text { new materials at the slope face (where eroded } \\
\text { materials are transported from the slope) }\end{array}$ & $\begin{array}{l}\text { Challenges to predict future } \\
\text { deterioration. Estimated strengths } \\
\text { could be conservative }\end{array}$ \\
\hline \multirow[b]{2}{*}{$\begin{array}{l}\text { Rock Mass } \\
\text { Strength }\end{array}$} & Intact Rock & $\begin{array}{l}\text { Processes primarily influence intact rock } \\
\text { matrix/fabric }\end{array}$ & $\begin{array}{l}\text { Negligible influence unless intensely } \\
\text { altered }\end{array}$ \\
\hline & Discontinuities & $\begin{array}{l}\text { Can have lesser influence on discrete } \\
\text { discontinuities but rather contributes to } \\
\text { overall rock mass break-up }\end{array}$ & $\begin{array}{l}\text { Reduction in shear strength where } \\
\text { weathering greater than the asperities } \\
\text { scale, impacting joint wall strength }\end{array}$ \\
\hline Groundwater & & $\begin{array}{l}\text { Significant influence on rock mass strengths } \\
\text { (e.g., chemical weathering) }\end{array}$ & $\begin{array}{l}\text { Lesser influence on rock mass } \\
\text { strengths }\end{array}$ \\
\hline
\end{tabular}

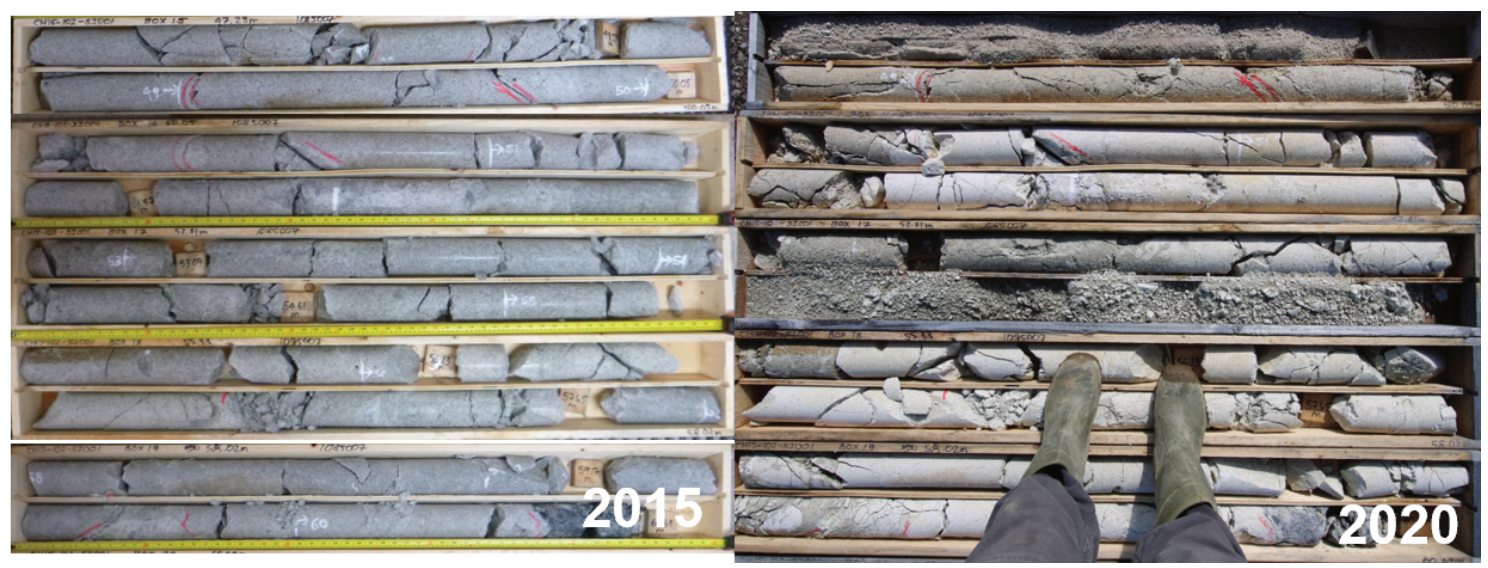

Figure 9 Quartz-feldspar porphyry core from $47 \mathrm{~m}$ to $60 \mathrm{~m}$ depth exhibiting variable quartz-kaolinite alteration intensities. Core when drilled (left) and after five years (right). 

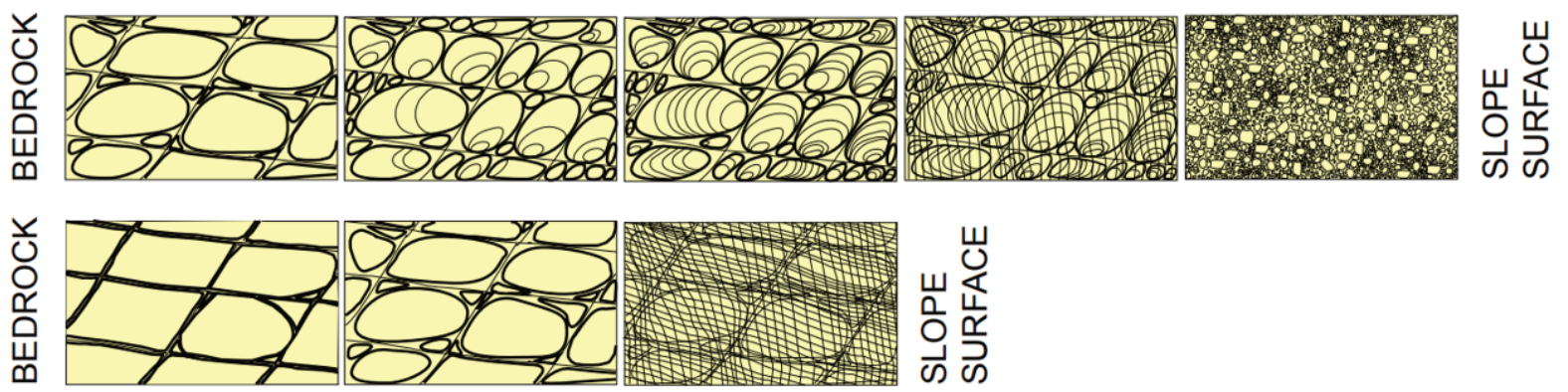

Figure 10 Changes in fracturing due to the development of incipient discontinuities (Cano et al, 2015)

\subsection{Design Criteria and Regulations}

Stability acceptance criteria presented in the guidance published by the LOP Project should be referred to when developing an assessment workplan (Read and Stacey, 2009). This overall stability criteria are based on the geotechnical model and estimated rock mass strength confidence, and the consequence of an instability event (e.g., water quality impacts from failure event entering a pit lake).

For closure studies, long-term stability should also consider design criteria for the site hydrogeology, hydrology and seismicity, and subsequent stability acceptance under these conditions. These three elements are particularly important for weak rocks as discussed throughout this paper. Table 2 outlines design criteria and considerations for a pit slope judged to have a high consequence of failure.

\section{Table 2 Design Criteria and Considerations for High Consequence Pit Slope Failure Event}

\begin{tabular}{|c|c|c|}
\hline Aspect & Item & Example Design Criteria or Consideration \\
\hline \multirow{5}{*}{$\begin{array}{l}\text { Geotechnical } \\
\text { and Stability }\end{array}$} & Geological models & High Confidence \\
\hline & $\begin{array}{l}\text { Existing overall } \\
\text { stability conditions }\end{array}$ & $\begin{array}{l}\text { Consequential failure event exhibits a FoS greater than } 1.5 \text { (static } \\
\text { conditions) and } 1.1 \text { (pseudo-static), PoF less than } 2.5-5 \% \text { (static). }\end{array}$ \\
\hline & $\begin{array}{l}\text { Overall Long-term } \\
\text { stability conditions1 }\end{array}$ & $\begin{array}{l}\text { Consequential failure event exhibits a FoS greater than } 1.5 \text { (static } \\
\text { conditions) and } 1.1 \text { (pseudo-static), PoF less than } 2.5-5 \% \text { (static). }\end{array}$ \\
\hline & $\begin{array}{l}\text { Consequential Back- } \\
\text { break2 }\end{array}$ & $\begin{array}{l}\text { Infrastructure located behind the back-break surface equal to FoS } \\
1.5 \text { and/or outside empirical/regulatory angles. }\end{array}$ \\
\hline & $\begin{array}{l}\text { Overall Pseudo- } \\
\text { static conditions }\end{array}$ & $\begin{array}{l}\text { Acceptable stability conditions under } 1,2475 \text {-year event (high } \\
\text { consequence) or } 10,000 \text {-year event (extreme consequence) }\end{array}$ \\
\hline \multirow{5}{*}{$\begin{array}{l}\text { Hydrogeological } \\
\text { and Hydrology }\end{array}$} & Precipitation & Infiltration resulting from maximum 24-hour duration event \\
\hline & Groundwater & $\begin{array}{l}\text { Acceptable stability conditions under long-term groundwater } \\
\text { conditions, including transient pore pressures } 3\end{array}$ \\
\hline & Pit Lake & $\begin{array}{l}\text { Acceptable stability conditions under predicted long-term lake } \\
\text { elevation. }\end{array}$ \\
\hline & Surface Water & Acceptance stability conditions linked to conveyance design4 \\
\hline & $\begin{array}{l}\text { Displaced pit lake } \\
\text { wave event }\end{array}$ & $\begin{array}{l}\text { Wave event produced by aa plausible failure event which doesn't } \\
\text { over-top into sensitive aquifer or impact critical mine } \\
\text { infrastructure. }\end{array}$ \\
\hline Geochemistry & Water Quality & Avoidance of adverse pit mixing due from event displacing water \\
\hline
\end{tabular}

Notes: 1 - long-term conditions utilizing predicted reduced strengths, 2 - back-break impacting critical infrastructure, 3 - can require calibrated and predicted groundwater modelling, 4 - hydrotechnical design to incorporate mitigation against seepage and over-topping 
Regulatory requirements differ between local, provincial/state, and federal jurisdictions. For example, in Canada most provinces or territories have specific closure requirements for open pits or surface voids. From the authors experience, guidance can be limited in some jurisdictions (or countries) where the mining industry is not well established. In this case, engineers and scientists should review multiple guidance documents from other jurisdictions.

\section{Case Study: Closure Design at Faro Mine Complex}

The Faro Mine Complex (FMC) is located approximately $20 \mathrm{~km}$ northwest of the town of Faro and $200 \mathrm{~km}$ north-northeast of Whitehorse, Yukon Territory. Pit slope stability assessments were completed for the Faro Pit North Wall to evaluate options for the long-term alignment of a non-contact diversion channel located upslope of the pit crest.

A primary study objective was to evaluate the long-term stability of two distinct zones that have exhibited slow creep, regression, and erosion during operation and continued following mining. The observed displacement is related to weak, altered Schist and Quartz Feldspar Porphyry units which are bound by major regional faults. A general outline of the study area and geological conditions are shown in Figure 11.

The future channel alignment is to be located upslope of back-scarp which corresponds to a plausible failure mechanism that exhibits a FOS equal or greater than 1.5, and where these is considered to have negligible impact on the water conveyance (e.g., formation of tension cracks close to the channel).
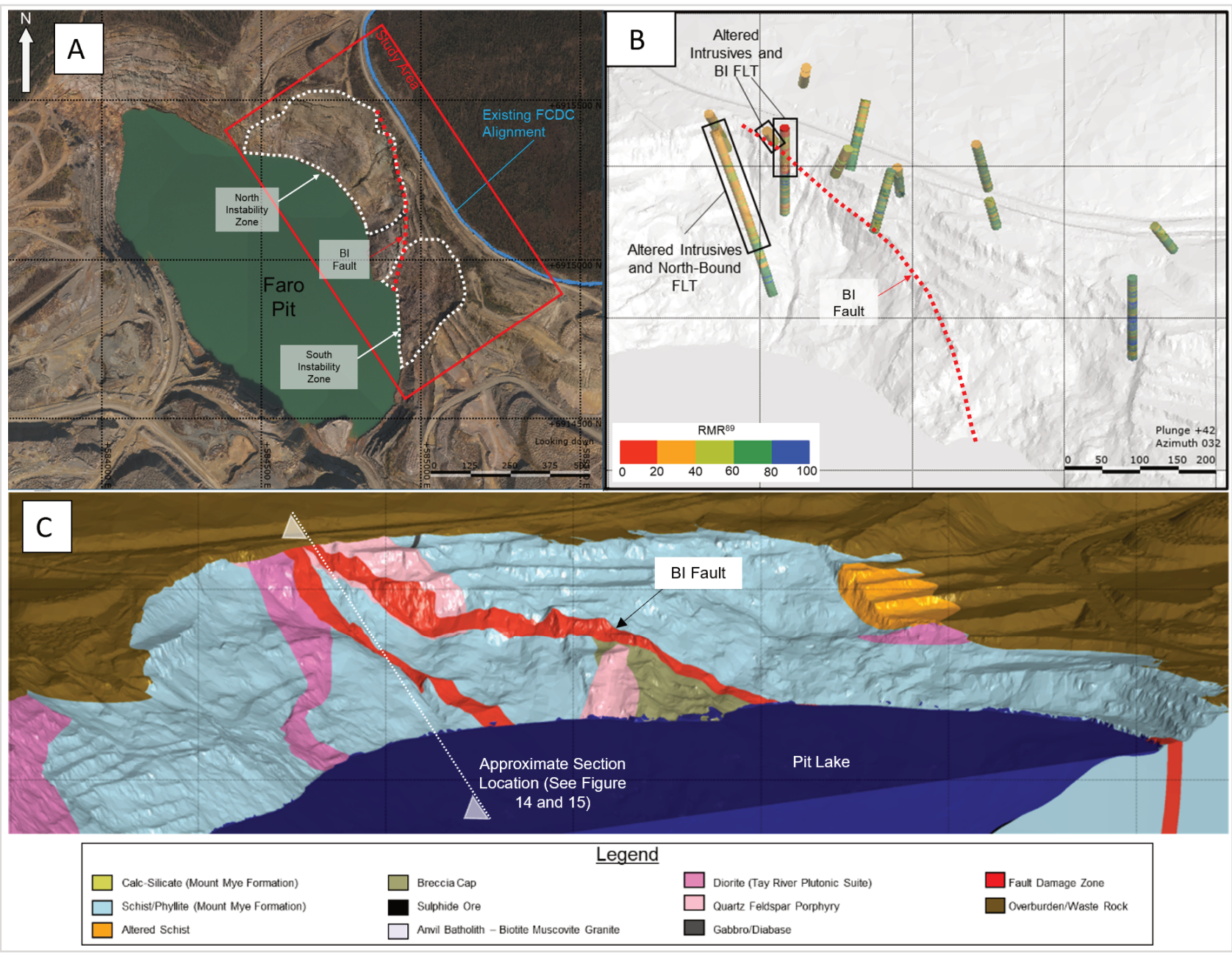

Figure 11 Faro Pit North Wall observed slope performance and generated 3D lithology/structural model 


\subsection{Geotechnical Investigation}

New and historical data was used to generate 3D geological/structural models (Figure 11), to determine rock mass strengths (current and predicted long-term) and to understand the slope performance. This investigation data included:

- Geological and geotechnical mapping of outcrop and rock cuts (limited by safe access). Historic bench slope and fault mapping collected during the operations were digitized.

- A total of 13 diamond drillholes across several closure studies (Figure 11). The recovered rock core was geotechnically logged, sampled and field tested.

- Rock strength laboratory testing including uniaxial compressive strength (UCS), UCS with modulus, tensile strength, single and multi-stage triaxial strength, direct shear, and soil classification.

- Downhole geophysics including televiewer, full-wave sonic velocity and gamma.

- Installation of one Time Domain Reflectometry and two Slope Inclinometers (SI).

- Interferometric Synthetic Aperture Radar (InSAR) study capturing a recent five-year period.

- Terrestrial, Light Detection and Ranging (LiDAR) and bathymetric surveys (Figure 13).

Importantly, significant care was taken to sample and test weak altered and fault gouge materials due to its implication on the modelled failure mechanisms

\subsection{Geology and Structural Geology Model}

Major geological units and a total of 21 faults were interpreted and modelled in 3D using Leapfrog ${ }^{\mathrm{TM}}$. The fault continuity and cross-cutting relationships were interpreted through evaluation of the data sources. The faults defined the contacts between the geological units to limits to the observed displacements. An example correlating available historic bench face mapping and infill drilling with more recent geotechnical drilling data to inform the fault geometry is shown in Figure 12.

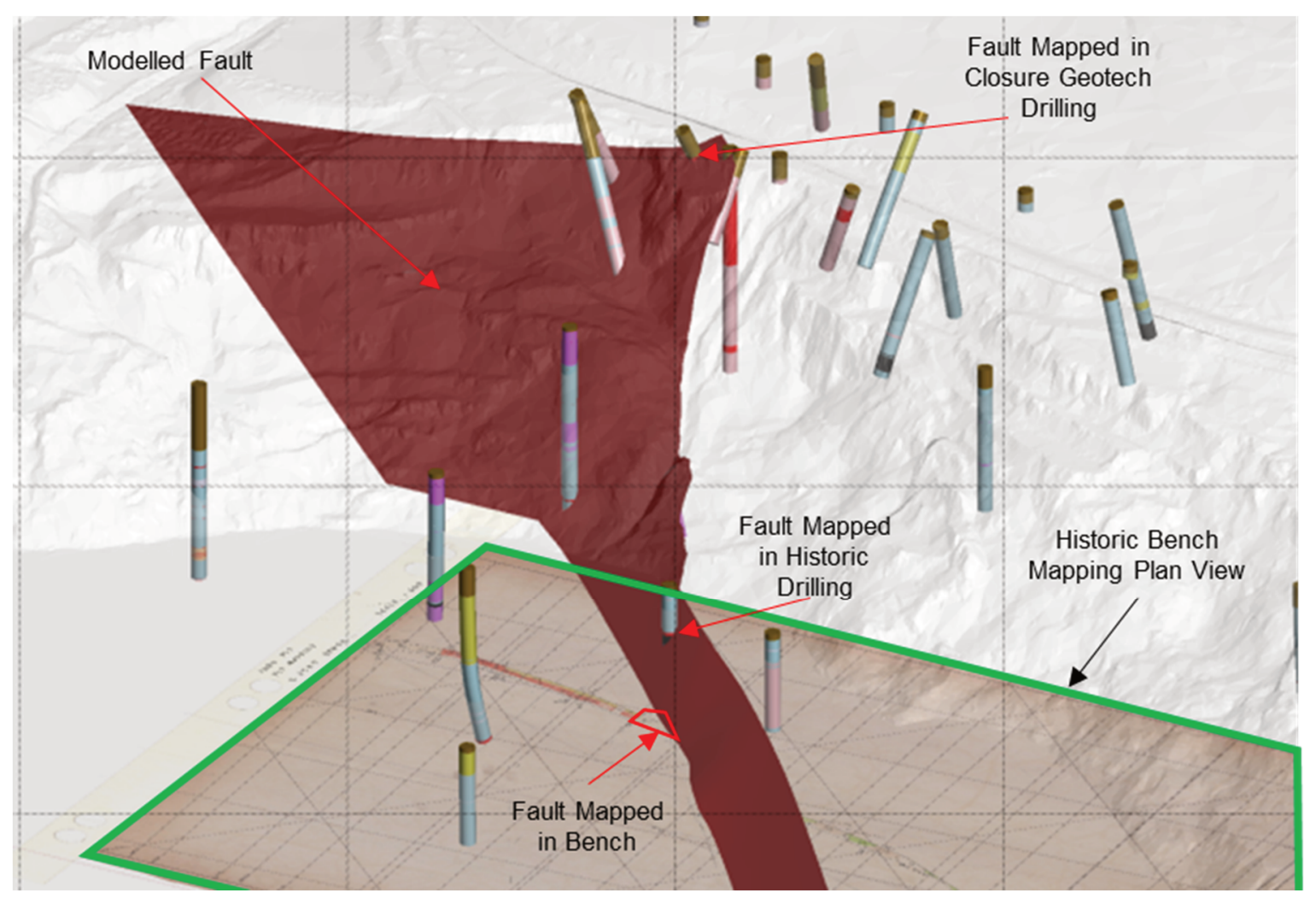

Figure 12 Use of historic mapping and drilling data to inform the litho-structural model geometry. 


\subsection{Monitoring}

The monitoring data was used to validate the failure mechanisms, including recent displacements and limits. The TDR, SI, InSAR and survey methods were cross matched against each other, and with the geological interpretations and stability analyses results. Figure 13 shows a change detection model between the endof-mine pit as-built survey and a composite of the 2018 aerial LiDAR and pit lake bathymetric surveys. The change detection shows good correlation with the weak rock material observed in drilling and slope face, and the probably limits of short- to medium-term displacements.

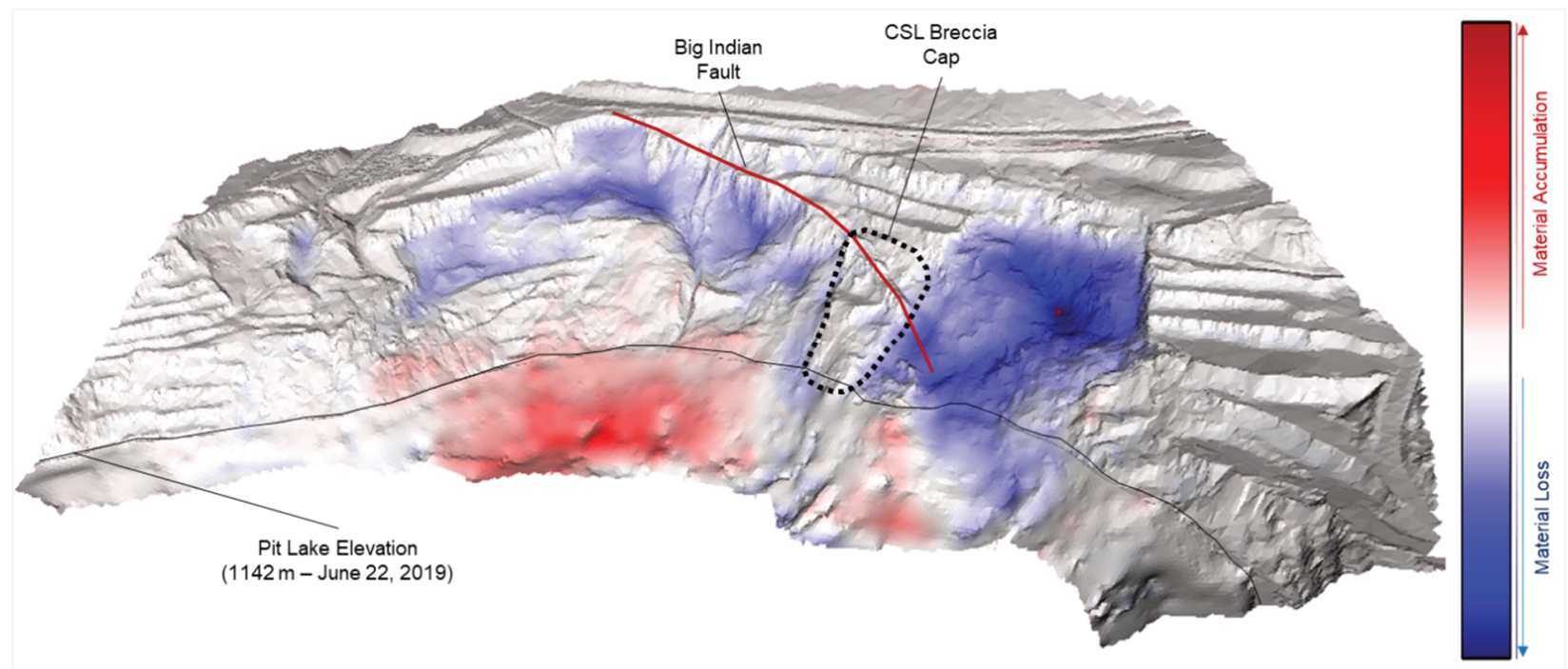

Figure 13 Change detection between 1991 pit as-built survey and merged 2018 Drone/bathymetry surveys. Red areas indicate material accumulation while blue indicate material loss

\subsection{Rock Mass Strength}

An important consideration was to evaluate the current and long-term rock mass strength. The long-term strengths for the weaker rock units more susceptible to deterioration were selected based on the $30^{\text {th }}$ percentile of investigated geotechnical strength datasets (which was similar to about $20 \%$ reduction in the average investigated parameters, Table 3). These datasets were derived from rocks that are considered to have been previously subjected to changes in stress and disturbance from the open pit mining. This longterm strength estimation was supported through testing of recently drilled core and core that has been exposed to ambient conditions over 5 years (Figure 9). However, this was only completed on core which remained intact and represented the more competent portion of the weak rock units. Table 3 outlines 2020 laboratory testing results on similar core collected from 2015 and 2020 programs. It should be noted that five years of exposure may be considered too short to be indicative of weathering at the 100-year scale, and the blanket of weathering materials continues to mitigate against the penetration of such a process into the slope, as shown schematically in Figure 8.

The 2015 core was also re-logged with compared against the original logging to semi-quantitively determine a deterioration scale due to the outside exposure (Figure 14). The re-logging and testing show apparent deterioration of the exposed core that in-situ would be located nearer to the major faults (Figure 14). 
Table 3 Summary of Laboratory Strength Testing from rock core within the Altered Quartz Feldspar Porphyry

\begin{tabular}{llllll}
\hline Testing Program & Drilling Program & Purpose & No. Samples & Mean (MPa) & \% Change \\
\cline { 2 - 5 } 2020 & 2020 & In Situ Strength & 6 & 50 & $-20 \%$ \\
& 2015 & Long-term Strength & 4 & 40 & \\
\hline
\end{tabular}

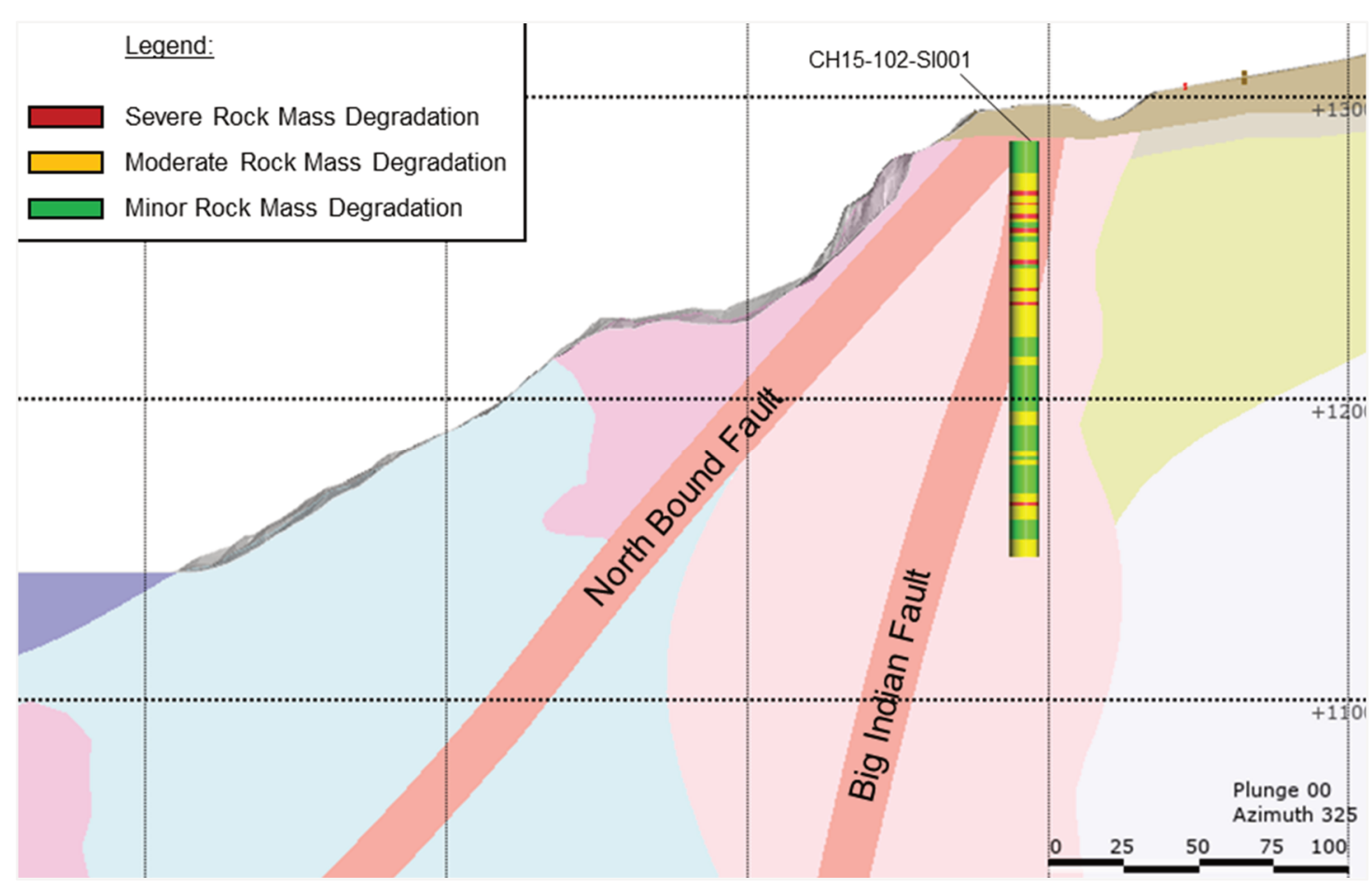

Figure 14 Apparent rock mass degradation over 5 years based on initial and re-logging of drill hole CH15-102-SI001 core (see Figure 11 for section location)

\subsection{Stability Assessment Approach and Design Criteria}

The design criteria used during the study is broadly similar to that described above in Table 2 . The expected overall stability conditions were assessed with multiple approaches using a combination of software packages, as summarized in Table 4. The analyses methods considered both 2D and 3D modelling efforts to best replicate the observed failure/displacement processes and to calibrate strength parameter from materials that were not easily investigated through drilling. Figure 15 shows a stability analysis case for the 'post failure geometry' where the short-to-medium term loss of slope face materials were accounted for. 
Table 4 Overview of stability assessment approach

\begin{tabular}{|c|c|c|}
\hline Slope Condition & Approach $^{1}$ & Software Utilized \\
\hline Current slope geometry & $\begin{array}{l}\text { 3D geometric fault interaction } \\
\text { 3D stability analyses - LE } \\
\text { 2D stability analyses - LE, FE and FD }\end{array}$ & $\begin{array}{l}\text { Leapfrog }^{\mathrm{TM}}, \\
\text { Slide2 }^{\mathrm{TM}} \cdot \mathrm{RS}^{\mathrm{TM}}, \\
\text { FLAC }^{\mathrm{TM}}, \text { Slide3 }^{\mathrm{TM}}\end{array}$ \\
\hline Post-failure slope geometry & 2D stability analyses - LE & Slide $2^{\mathrm{TM}}$ \\
\hline $\begin{array}{l}\text { Current slope geometry with } \\
\text { long-term rock mass strength }\end{array}$ & $\begin{array}{l}\text { Observed slope performance and monitoring } \\
\text { Re-logging and testing of degraded core } \\
\text { 2D stability analyses - LE }\end{array}$ & $\begin{array}{l}\text { Leapfrog }^{\mathrm{TM}} \\
\text { Slide }^{\mathrm{TM}}\end{array}$ \\
\hline $\begin{array}{l}\text { Back-break -positioning } \\
\text { alignment upslope of scarp } \\
\text { where FoS equal or greater than } \\
1.5\end{array}$ & $\begin{array}{l}\text { 3D geometric fault interaction } \\
\text { 2D stability analyses - LE, FE and FD }\end{array}$ & $\begin{array}{l}\text { Leapfrog }^{\mathrm{TM}} \\
\text { Slide2 }^{\mathrm{TM}} \cdot \mathrm{RS}^{\mathrm{TM}} \\
\mathrm{FLAC}^{\mathrm{TM}}\end{array}$ \\
\hline
\end{tabular}

Notes: ${ }^{1}$ LE $=$ Limit Equilibrium Model, FE = Finite Element Model, FD = Finite Difference Model

The analyses approaches included fault kinematic, limit-equilibrium and deformation modelling due to the complex geotechnical conditions, and the requirement to confidently evaluate the long-term stability condition. Deformation analyses were used to provide more confidence in the evaluations for predicting the relative location of tension cracking that could potentially contribute to infiltration from the channel.

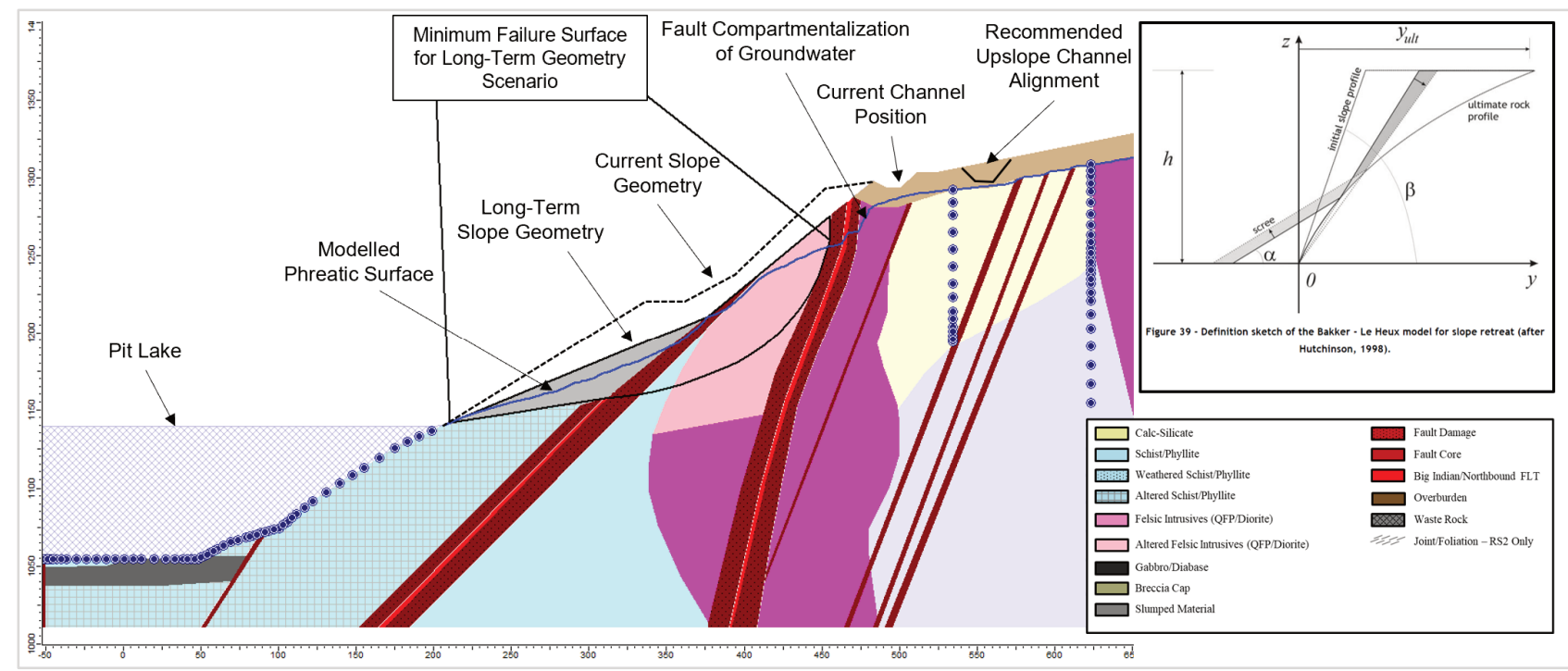

Figure 15 Faro Pit stability section considering potential long-term slope geometry. Inset includes schematic of slope retreat due to progressive degradation (after Hutchinson, 1998).

\section{$4 \quad$ Results and Conclusions}

As described throughout the paper, when assessing the post-operation stability of an open pit, many timedependent mechanisms need to be considered where developing a robust work plan in weak rocks. Among them, some of the most important to properly characterize include the susceptibility to severe erosion or deterioration of any weaker units. Such progressive failure mechanisms can be further negatively influenced by the post-mining hydrogeological conditions. Design acceptance criteria should not only reflect this timedependent variability but also the potential impact a slope failure may have on other critical closure infrastructure, which are vital to achieving the site closure objectives. 
The FMC case study shows examples of the considerations that were incorporated into the assessment workplan. Several long-term stability scenarios evaluated to determine the alignment of a non-contact water channel that was required to upslope of the back-scarp for a plausible failure event exhibiting a FoS of 1.5 or greater. This work also including deformation analyses to evaluate the formation of downslope tension cracks that could impact water conveyance along the channel.

As environmental stewardship continues to drive more innovative approaches in the mining industry, more detailed engineering analyses such as that undertaken at Faro can provide greater confidence and reliability in the outcome of the proposed closure design.

\section{Acknowledgement}

The authors would like to acknowledge Crown-Indigenous Relations and Northern Affairs Canada (CIRNAC) for the support and willingness to share the work completed at the Faro Mine Complex. The authors would also like to thank valuable correspondence with Marco Huisman and Robert Hack whose work have made valuable contributions to the overall artificial slope weathering subject.

\section{References}

Cano, M \& Tomas, R, \& Riquelme, A 2016, 'Preliminary relationship between weathering behaviour profiles and laboratory slake behaviour of carbonatic flysch rocks'. In Proceedings from Eurorock 2016.

De Bruyn, I, Prado, D, Mylvaganam, J \& Walker, D 2019, 'Geotechnical Considerations for the Stability of Open Pit Excavations at Mine Closure: Some Scenarios', in AB Fourie \& M Tibbett (eds), Proceedings of Mine Closure 2019, Australian Centre for Geomechanics, Perth, pp. $235-248$.

De Graaf, PJH, Desjardins, M \& Tsheko, P 2019, 'Geotechnical risk management for open pit mine closure: a sub-arctic and semi-arid case study', in AB Fourie \& M Tibbett (eds), Proceedings of the 13th International Conference on Mine Closure, Australian Centre for Geomechanics, Perth, pp. 211-234

Hack, HRGK 2000, 'Weathering, Erosion, and Susceptibility to Weathering', in Jani, M, He, M and Riberira E Sousa, L (eds), Soft Rock Mechanics and Engineering, $1^{\text {st }}$ ed, Ch. 11, Cham, Switzerland.

Huisman, M, Hack, HRGK \& Nieuwenhuis, JK 2006, 'Predicting Rock Mass Decay in Engineering Lifetimes: The Influence of Slope Aspect and Climate', Journal of Environmental and Engineering Geoscience, vol. 12, no. 1, pp. 39-51.

Hutchinson, JN 1998, 'A Small-Scale Field Check on the Fisher-Lehmann and Bakker-Le Heux Cliff degradation Models'. Journal of Earth Surface Processes and Landforms, vol. 23, pp.913-916.

Fookes, PG, Gourley, CS \& Ohikere, C 1988, 'Rock Weathering in Engineering Time', Quarterly Journal of Engineering Geology, vol. 21, no. 1, pp. 33-57.

Martin D, \& Stacey, P 2018. Guidelines to Open Pit Slope Design in Weak Rocks. CSRIO Publishing.

McCullough CD, Schultze M, Vandenberg J 2020 'Realising beneficial end uses from abandoned pit lakes'. Minerals vol. 10 pp. 133

Murphy, B \& Barnett, W 2018, 'Approach to Geotechnical Characterization and Slope Design Data Acquisition Programs In Different Deposit Types', in Proceedings of the 2018 International Symposium on Slope Stability in Open Pit Mining and Civil Engineering, Asociacion Nacional de Ingenieros de Minas, Seville, pp. 1315-1329.

Peltier, L 1950. 'The Geographic Cycle in Periglacial Regions as it is Related to Climatic Geomorphology'. Annals of The Association of American Geographers vol. 40, no. 3, pp. 214-236

Read, J \& Stacey, P 2009. Guidelines to Open Pit Slope Design. CSIRO Publishing.

Shinjo, T \& Ito, T 1989, 'Slope excavation, In Recent Advances in Soft Rock Research', Rept. of ISSMFE Tech. Com. Soft Rocks and Ind. Soils and Proc. Disc. Ses. 5, Rio de Janeiro, Brazil, pp. 31-43. 